\title{
Šestdeset let spraševanja "Kdo sem jaz?": Analiza vprašalnika Twenty Statements Test (TST)
}

Oddelek za psihologijo, Filozofska fakulteta, Univerza v Mariboru

Povzetek: Leta 1954 sta Kuhn in McPartland v kontekst raziskovanja posameznikovega pojmovanja sebe oziroma sebstva postavila enostavno vprašanje »Kdo sem jaz?«. V kasnejših letih je ta preizkus postal popularen na področju psihološkega in sociološkega raziskovanja, v zadnjem času pa je aktualen na področju medkulturnih (psiholoških) študij. Po 60 letih smo si omenjeno vprašanje zastavili znova, in sicer v kontekstu analitičnega pregleda preteklih raziskav omenjenega instrumenta, $\mathrm{s}$ čimer poskušamo $\mathrm{v}$ celoviti evalvaciji odgovoriti tudi na vprašanje, ali je uporaba omenjenega vprašanja $\mathrm{v}$ raziskovalne namene dandanes še smiselna.

Ključne besede: Kdo sem jaz?, Preizkus dvajsetih izjav, pojmovanje sebe, sebstvo, analiza vprašalnika

\section{Sixty years of asking "Who am I?": Analysis of the Twenty Statements Test (TST)}

\author{
Bojan Musil* and Andrej Preglej \\ Department of psychology, Faculty of Arts, University of Maribor, Slovenia
}

\begin{abstract}
In 1954, Kuhn and McPartland set a simple question "Who am I?" in the context of the research of self and selfconcept. In later years, the questionnaire become popular in psychological and sociological research, while in recent times it was widely used in the field of cross-cultural (psychological) studies. After 60 years, we have asked that question again in the context of analytic review of past research of this instrument. In the overall evaluation of the instrument, we try to answer the question whether the use of the question is still scientifically meaningful.
\end{abstract}

Keywords: Who am I?, Twenty Statements Test (TST), self-concept, self, questionnaire analysis

\footnotetext{
"Naslov/Address: Bojan Musil, Oddelek za psihologijo, Filozofska fakulteta, Univerza v Mariboru, Koroška cesta 160, 2000 Maribor, e-pošta: bojan.musil@um.si 
Med preprostimi vsakdanjimi vprašanji je le redko katero pritegnilo toliko raziskovalne pozornosti kot vprašanje »Kdo sem jaz?«. V preteklosti so se z omenjenim vprašanjem, ki posameznike napeljuje $\mathrm{k}$ razkrivanju lastnega dojemanja oziroma pojmovanja sebe, raziskovalno precej ukvarjali večinoma psihologi in sociologi, v današnjem času pa ga v kontekstu medkulturnih študij uporabljajo pretežno socialni psihologi. Še vedno pa obstaja velika verjetnost, da se študenti psihologije ali sociologije $\mathrm{z}$ omenjenim vprašanjem srečajo vsaj enkrat v času svojega študija.

$\mathrm{V}$ pričujočem prispevku bomo predstavili vprašalnik »Who am I?« (oziroma v slovenski različici »Kdo sem jaz?«) ali V drugačnem poimenovanju tudi Twenty statements test (TST; ki bi ga lahko slovenili kot Preizkus dvajsetih izjav), ki sta ga leta 1954 razvila Kuhn in McPartland kot poskus uvedbe standardiziranega načina merjenja predpostavk in stališč do sebe. $\mathrm{V}$ nadaljevanju bomo prikazali krajši analitični pregled preteklih raziskav na omenjenem instrumentu, ki bo poskušal podati tudi evalvacijo samega instrumenta ter njegove uporabe.

\section{Nastanek in razvoj TST}

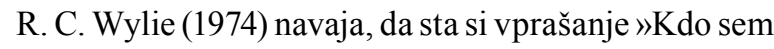
jaz?« z namenom preučevanja pojmovanja sebe oziroma sebstva kot prva zastavila Bugental in Zelen leta 1950, vendar pa je omenjeno vprašanje, operacionalizirano $\mathrm{v}$ celovit instrument TST postalo raziskovalno prepoznavno $\mathrm{z}$ avtorjema Manfordom H. Kuhnom in Thomasom S. McPartlandom v članku An empirical investigation of self-attitudes (Kuhn in McPartland, 1954).

Omenjena avtorja sta ustvarila preprost instrument, $\mathrm{s}$ katerim sta poskušala identificirati in izmeriti stališča osebe do samega sebe. V izvirni različici TST posameznik dobi list papirja $\mathrm{z}$ navodilom, da poda različne odgovore na vprašanje »Kdo sem jaz?« in jih zapiše na dvajset praznih črt, pri čemer jih lahko zapisuje v poljubnem vrstnem redu in v časovni omejitvi 12 minut (Kuhn in McPartland, 1954).

Teoretsko sta se Kuhn in McPartland vkonceptualizaciji TST navezala na področje simbolnega interakcionizma. Če povzamemo po poglavitnem predstavniku slednjega, Meadu (1934), lahko sebstvo ali pojmovanje sebe vidimo kot objekt, za katerega ima vsak subjekt določen načrt, kako ga obravnavati oziroma se do njega skladno obnašati. $\mathrm{Na}$ podlagi tega sta avtorja nadalje sklepala naslednje: »Človeško obnašanje je organizirano in usmerjeno. Organiziranost in usmerjenost pa sta produkt stališč, ki jih ima posameznik o sebi.« (Kuhn in McPartland, 1954, str. 68). Posledično sta bila mnenja, da je pomembno identificirati in meriti stališča oziroma celovit odnos, ki ga ima posameznik do sebe.

Že v izvorni različici TST je bil pomemben vidik instrumenta kodiranje odgovorov. Kuhn in McPartland (1954) sta v okviru slednjega predpostavila dve kategoriji odgovorov: konsenzualne (angl. consensual) in podkonsenzualne (angl. subconsensual) izjave. Konsenzualne izjave se nanašajo na dogovorjene izjave, ki jih lahko srečamo pri vseh članih določene kulture, kot so npr. študent, hčerka, oče, strojnik, Kristjan. Točen pomen podkonsenzualnih izjav pa je znan samo tistemu posamezniku, ki jih napiše, kot so npr. dobre volje, interesanten, dolgočasen, težka oseba (prim. Kuhn in McPartland, 1954).

Leta 1960 je Kuhn izvedel obsežno raziskavo na 1185 ljudeh. Kodiranje instrumenta je elaboriral na pet kategorij, in sicer: 1) socialne skupine in klasifikacija (spol, starost, rasa, religioznost, zakon); 2) ideološka verovanja (izjave religiozne, filozofske ali moralne narave); 3) interesi (izjave, ki se nanašajo na objekt v povezavi s sebstvom, ki so bodisi pozitivne bodisi negativne); 4) ambicije (vse izjave, ki se nanašajo na prihodnost in uspešnost) in 5) samoevalvacija (vrednotenje fizičnega videza, vrednotenje psihičnih sposobnosti, povezanost z drugimi, altruizem, prejšnji dosežki itd.).

Zanimivi so tudi drugi izsledki omenjene raziskave. Kot ugotavlja Kuhn (1960), se posameznik začne po sedmem letu življenja identificirati oziroma čutiti povezanega $z$ večjimi skupinami v družbi. Po drugi strani pa s starostjo število identifikacijskih skupin upada. Nadalje ženske $\mathrm{v}$ primerjavi $\mathrm{z}$ moškimi $\mathrm{v}$ odgovorih pogosteje navedejo spol (med prve tri izjave kar v $78 \%$ primerih, moški pa za $12 \%$ manj). Razlago za navedeno je avtor navezal na podrejenost žensk v zahodnem svetu (zlasti v 1960. letih prejšnjega stoletja v Ameriki), zaradi česar ženske pogosteje navajajo svojo spolno identiteto. Nadalje Kuhn izpostavlja, da se študenti po vsakem zaključenem letniku bolj identificirajo s področjem, za katerega se izobražujejo. S tem naj bi se potrjevala socialno-interakcionistična predpostavka, da je »oseba sama sebi objekt« oziroma »objekt, katerega pomen o samem sebi in ostalih izvira iz sistema socialnih objektov, katerih del je« (Kuhn, 1960, str. 53).

Leto kasneje so McPartland, Cumming in Garretson (1961) izvedli raziskavo, v kateri so uporabili kodiranje, ki naj bi predstavljalo osnovo za vse potencialne sheme kodiranja $\mathrm{v}$ prihodnosti. Kodiranje so razdelili v štiri kategorije: A - fizično (starost, spol, naslov stanovanja, barva oči in las); B - statusi in vloge v socialnem okolju (sem oče, sem katolik, kitarist); C - občutki in načini obnašanja v različnih situacijah (včasih sem slabe volje, rada sem v družbi, strah me je novih stvari); D - univerzalno (splošna kategorija; izjave, pri katerih se posameznik ne nanaša na nobeno skupino oziroma preseže socialno interakcijo in zavezo socialnim normam, npr. vsem želim najboljše, skušam biti boljši ... tudi izjave kot sem živo bitje, sem eno z bogom, sem inteligenca, sem prah). Po avtorjih naj bi si kategorije sledile $\mathrm{v}$ sosledju od fizične strukture $\mathrm{v}$ času in prostoru (A), prek pojmovanj sebstva v odnosu do socialne strukture (B) in socialne interakcije, ločene od socialne strukture (C), do pojmovanja sebstva, ločenega od fizičnih značilnosti, socialne strukture in socialne interakcije (D) (McPartland, Cummings in Garretson, 1961). 
Omenjena raziskava je imela jasno zastavljeno praktično vrednost, saj so jo izvedli na psihiatričnem oddelku z namenom, da bi lahko na podlagi samoopisov napovedovali obnašanje pacientov oz. njihovo interakcijo z bolniškim osebjem. Predpostavili so, da bo za osebe, ki bi napisale v povprečju največ odgovorov $\mathrm{A}$ in posledično sodijo v to kategorijo, veljalo, da ne iščejo in ne potrebujejo stikov z drugimi. Tisti, ki sodijo v kategorijo B, naj bi prav zaradi svoje zavezanosti družbi sledili normam na psihiatričnem oddelku in izkazovali višjo stopnjo konformnosti. Kategorija $\mathrm{C}$ naj bi po predvidevanjih avtorjev v primerjavi s skupinama A in B predstavljala bolj uporniško skupino, saj te osebe zaznavajo sebe kot pomembnejše od socialnih pravil. Najtežavnejša glede na osnovni cilj raziskave pa naj bi bila kategorija $\mathrm{D}$, saj so opisi v tej kategoriji najbolj oddaljeni od konkretnih (socialnih) kontekstov in interakcij, takšni posamezniki pa so $\mathrm{v}$ tej transcendentni naravi opisov pogosto nad družbenimi pravili in normami. Na podlagi naknadne izvedbe intervjujev $\mathrm{z}$ oddelčnimi medicinskimi sestrami so avtorji svoje napovedi potrdili (McPartland, Cummings in Garretson, 1961).

Po tem začetnem obdobju se je TST uveljavil kot ena od tehnik merjenja pojmovanja o sebi ali sebstva. Raziskovalci so povzeli osnovni namen in navodilo izvorne različice instrumenta; modifikacije so bile potencialno prisotne zgolj pri izvedbi in kodiranju odgovorov, hkrati pa se je z leti spreminjal sam okvir raziskav, in sicer od raziskav, osredotočenih na posameznika v različnih (konkretnih) socialnih kontekstih, v raziskovanje različnosti v najširših sociokulturnih kontekstih (medkulturne študije).

Med širšimi in preglednejšimi analizami TST $\mathrm{s}$ področja medkulturnih študij lahko navedemo dve metaanalizi sodobnejšega časa. Church (2009) je opravil metaanalizo na podlagi TST, v kateri je preučeval, katere osebnostne lastnosti oziroma poteze kultura poudarja in če se le-te kažejo pri posameznikih. Podobno metaanalizo, ki jo dopolnjuje raziskava, je izvedla del Pradova s sodelavci (2007). V njej so preučevali koncept sebstva V individualističnih in kolektivističnih kulturah.

\section{Analiza TST raziskav}

$\mathrm{V}$ pregledu preteklih raziskavah TST nismo zasledili znanstvenih prispevkov, ki bi v ospredje postavili sam instrument in preučevali njegove psihometrične lastnosti, različne možnostmi kodiranja in njegovo uporabno vrednost. Iz tega razloga v nadaljevanju podajamo analizo TST, s poudarkom na namenu uporabe testa in njegovih psihometričnih lastnostih, ter celovito evalvacijo uporabe omenjenega instrumenta.

$\mathrm{V}$ analitičnem pregledu raziskav TST smo $\mathrm{v}$ v prvi fazi $v$ znanstvene baze (JSTOR, EBSCOhost, SAGE, ScienceDirect) vnesli besede »twenty statements test « in/ ali »TST«, ter »who am I« in/ali »WAI«. Skupno število znanstvenih prispevkov, ki smo jih pridobili v znanstvenih bazah, je znašalo 592. V drugi fazi smo v pridobljenem naboru iskali članke, ki so med drugim obravnavali tudi sam instrument in njegove psihometrične lastnosti, v nadaljnjo analizo pa vključili samo članke, ki so uporabili originalna navodila po Kuhnu in McPartlandu (1954), saj v nasprotnem primeru ne moremo več govoriti o TST, temveč o nekem drugem testu, kot je npr. Foelsova in Tomchova (2009) modifikacija v obliko t.i. Testa izjav o socialni identiteti (Social Identity Statements Test; SIST). $\mathrm{V}$ ožji izbor je prišlo 40 znanstvenih člankov.

$\mathrm{V}$ tabeli 1 je prikaz 15 raziskav $\mathrm{z}$ opisom namena, načinom kodiranja odgovorov in zanesljivostjo testa. Navedene so tiste raziskave, ki kar najbolje predstavljajo različne načine kodiranja odgovorov.

Kot je razvidno iz prikaza, je večina raziskav usmerjena $\mathrm{v}$ primerjanje samoopisov med različnimi kulturami ali med določenimi socialnimi kategorijami (npr. spol, rasa). Ne glede na način ugotavljanja skladnosti med ocenjevalci (korelacija, odstotek ujemanja, koeficient kappa) lahko zaključimo, da je stopnja zanesljivosti na dokaj visoki stopnji ne glede na raznolikost načinov kodiranja odgovorov. Prav slednje pa podrobneje analiziramo v nadaljevanju, saj so kodiranja odgovorov v tabeli 1 prikazana bolj posplošeno in so v raziskavah bolj elaborirana.

Cousins (1989) je podrobneje razdelal C (osebno) in D kategorijo (globalno). V celoti je bila $\mathrm{C}$ kategorija sledeča: preference ( $\mathrm{Cl}$ - »rad imam čokoladni sladoled «); cilji, želje (C2 - »želim postati zdravnik«); aktivnosti, navade (C3 - »berem znanstvene članke«); kvalificirane psihološke poteze (C4), ki vključujejo reference na druge ljudi (»šalim se z bližnjimi prijatelji«), na čas (»zjutraj sem slabe volje «) in na prostor (»V učilnici sem zgovoren «); čiste psihološke lastnosti (C5) so nevezane na kontekst (»iskren sem«). D kategorija je bila razdeljena na opis, $\mathrm{s}$ katerim se posameznik opisuje na individualen in abstrakten način (»edinstvena kreacija«, »individuum«), ali pa se opisuje kot nediferencirani univerzalen član (»)jaz sem sesalec«, »jaz sem produkt okolja«). V kategoriji objekt (O) so zbrani vsi odgovori, ki jih ni bilo mogoče umestiti v zgoraj navedene kategorije (Cousins, 1989).

Bond in Cheung (1983) sta podrobneje razdelala tri kategorije. Kategorija socialne identitete (A) je sestavljena iz osebnih podatkov (»ime mi je XX«, »živim v YY«; avtorja sta to podkategorijo poimenovala »Self«), vlog (najstnik, študent, hčerka) in socialnih kategorij, v kateri so izjave, ki se nanašajo na splošne abstraktne pojme (podobno kot D kategorija pri Cousinsu, 1989). Osebni atributi (B) so razdeljeni na fizične atribute (barva oči in las, višina, teža); izbire, ki kažejo na posameznikove preference (rad igram nogomet; ni mi všeč vaterpolo); aspiracije (želim postati umetnik); prepričanja (verjamem v Boga; verjamem, da so ljudi v resnici dobri); splošne psihološke atribute (sem introverten, sem razdražljiv). Zadnja kategorija so osebna dejstva (C), ki zajemajo izjave, ki se nanašajo na točno določeni dogodek (včeraj sem bil v kinu), situacijo (živim s starši) in lastnino (imam psa). Druga podkategorija pa so odgovori, ki jih ni bilo možno umestiti v zgoraj navedene kategorije. Bond in Cheung (1983) sta ocenjevala tudi valenco odgovorov oziroma ali imajo odgovori pozitivno ali negativno konotacijo. 
Tabela 1. Primeri raziskav z različnimi kodiranji TST in zanesljivostjo med ocenjevalci

\begin{tabular}{|c|c|c|c|}
\hline Avtor/ji & Namen študije & Kodiranje - kategorije & $\begin{array}{l}\text { Zanesljivost } \\
\text { (med ocenjevalci) }\end{array}$ \\
\hline Bond in Cheung (1983) & $\begin{array}{l}\text { Koncept sebstva med } \\
\text { kitajskim, japonskim in } \\
\text { ameriškim študentom. }\end{array}$ & $\begin{array}{l}\text { A. socialna identiteta; B. osebni atributi; } \\
\text { C. osebna dejstva }\end{array}$ & $\begin{array}{l}\text { Podatki pod } 70 \% \\
\text { skladnosti med } \\
\text { ocenjevalci niso } \\
\text { obravnavani. }\end{array}$ \\
\hline Cousins, (1989) & $\begin{array}{l}\text { Samozaznavanje Japoncev in } \\
\text { Američanov. }\end{array}$ & $\begin{array}{l}\text { A. fizično; B. socialno; C. osebno; D. } \\
\text { globalno; O. objekt }\end{array}$ & Povprečje $r=0,87$ \\
\hline $\begin{array}{l}\text { Dhawan, } \\
\text { Roseman,Naidu, Thapa } \\
\text { in Rettek (1995) }\end{array}$ & $\begin{array}{l}\text { Koncept sebstva med Indijci } \\
\text { in Američani. }\end{array}$ & $\begin{array}{l}\text { A. socialna identiteta; B. ideološka } \\
\text { verovanja; C. interesi; D. cilji; E. } \\
\text { samoocena; F. ostalo }\end{array}$ & Povprečje $r=0,86$ \\
\hline Driver (1969) & $\begin{array}{l}\text { Validacija koncepta sebstva } \\
\text { oz. primerjanje samoopisov } \\
\text { med Američani in Indijci. }\end{array}$ & $\begin{array}{l}\text { 1. korak: A. socialne skupine; B. } \\
\text { ideološka verovanja; C. interesi, D. } \\
\text { ambicije; E.samoevalvacija. } \\
\text { 2. korak: A. konsenzualni stavki; B. } \\
\text { podkonsenzualni stavki }\end{array}$ & - \\
\hline $\begin{array}{l}\text { Kanagawa, Cross in } \\
\text { Markus (2001) }\end{array}$ & $\begin{array}{l}\text { Koncept sebstva med } \\
\text { japonskimi in ameriškimi } \\
\text { študenti. }\end{array}$ & $\begin{array}{l}\text { A. fizično; B. socialno, C. osebno; } \\
\text { D. samonanašalne izjave; E. trenutna } \\
\text { situacija; F. mnenja drugih; G. lastnina; } \\
\text { H. mešano }\end{array}$ & Povprečje $r=0,98$ \\
\hline $\begin{array}{l}\text { Ma in Schoeneman } \\
\text { (1997) }\end{array}$ & $\begin{array}{l}\text { Primerjanje samoopisov } \\
\text { Afričanov in Američanov. }\end{array}$ & $\begin{array}{l}\text { A. pripisane lastnosti; B. vloge in } \\
\text { članstvo; C. abstraktno identificiranje; } \\
\text { D. interesi in aktivnosti; E. materialne } \\
\text { reference; F. sistemski čut sebstva; G. } \\
\text { osebne karakteristike; H. zunanji pomen }\end{array}$ & $r=0,95$ \\
\hline $\begin{array}{l}\text { Madson in Trafimov } \\
\text { (2001) }\end{array}$ & $\begin{array}{l}\text { Primerjanje koncepta sebstva } \\
\text { med spoloma. }\end{array}$ & $\begin{array}{l}\text { A. izjave privatne kognicije; B. izjave } \\
\text { kolektivne kognicije; C. alocentrične } \\
\text { izjave }\end{array}$ & $\begin{array}{l}\text { Kappa koeficient } \\
\kappa=0,98\end{array}$ \\
\hline $\begin{array}{l}\text { Rhee, Uleman, Lee in } \\
\text { Roman (1995) }\end{array}$ & $\begin{array}{l}\text { Razlika v samoopisih } \\
\text { pripadnikov individualistične } \\
\text { (Američani) in kolektivistične } \\
\text { (Korejci) kulture. }\end{array}$ & $\begin{array}{l}\text { A. lastnosti; B. socialne identitete; C. } \\
\text { specifični atributi; D. ocenjevalni opisi; } \\
\text { E. fizični opisi; F. počutje; G. periferne } \\
\text { informacije; H. globalni opisi. }\end{array}$ & Povprečje $r=0,94$ \\
\hline $\begin{array}{l}\text { Santamaria, de la Mata, } \\
\text { Hansen in Ruiz (2010) }\end{array}$ & $\begin{array}{l}\text { Razlike v pojmovanju sebe } \\
\text { med mehiškimi, španskimi in } \\
\text { danskimi študenti. }\end{array}$ & $\begin{array}{l}\text { A. privatni samoopisi; B. kolektivni } \\
\text { samoopisi; C. javni samoopisi }\end{array}$ & $\begin{array}{l}\text { Povprečje kappa } \\
\text { koeficienta } \kappa=0,90\end{array}$ \\
\hline $\begin{array}{l}\text { Steck, Heckert in } \\
\text { Heckert (2003) }\end{array}$ & $\begin{array}{l}\text { Pomen rasne identitete } \\
\text { Afroameričanov in belcev. }\end{array}$ & $\begin{array}{l}\text { Katero mesto zavzame omenjanje rase v } \\
20 \text { postavkah in kolikokrat je omenjeno. }\end{array}$ & - \\
\hline $\begin{array}{l}\text { Triandis, McCusker in } \\
\text { Hui (1990) }\end{array}$ & $\begin{array}{l}\text { Razlika med samoopisi } \\
\text { v individualistični in } \\
\text { kolektivistični kulturi. }\end{array}$ & $\begin{array}{l}\text { Točkovali so izjave, ki se nanašajo na } \\
\text { skupino ali demografsko kategorijo, s } \\
\text { katero si posameznik lahko deli nekaj } \\
\text { skupnega. }\end{array}$ & $r=0,97$ \\
\hline Vernon (1962) & $\begin{array}{l}\text { Preverjanje religioznosti } \\
\text { posameznikov. }\end{array}$ & $\begin{array}{l}\text { Točkovale so se izjave, ki izražajo } \\
\text { religioznost. }\end{array}$ & - \\
\hline Watkins idr. (2003) & $\begin{array}{l}\text { Razlike med spoloma } \mathrm{v} \\
\text { konceptu sebstva v več } \\
\text { različnih kulturah. }\end{array}$ & $\begin{array}{l}\text { A. idiocentrično; B. majhna skupina; C. } \\
\text { velika skupina; D. alocentrično }\end{array}$ & $\begin{array}{l}\text { Nad } 90 \% \text { skladnost } \\
\text { med ocenjevalci. }\end{array}$ \\
\hline $\begin{array}{l}\text { Watkins in Gerong } \\
\text { (1997) }\end{array}$ & $\begin{array}{l}\text { Razlika med konceptom } \\
\text { sebstva med Filipinci, Kitajci } \\
\text { in Američani. }\end{array}$ & $\begin{array}{l}\text { A. socialne vloge; B. self; C. globalna } \\
\text { identiteta; D. fizične karakteristike; E. } \\
\text { zdravje; F. cilji; G. želje, H. upanja; } \\
\text { I. stališča; J. sposobnosti; K. posebni } \\
\text { življenjski dogodki; L. psihološki } \\
\text { atributi; M. ostalo }\end{array}$ & $r=0,85$ \\
\hline $\begin{array}{l}\text { Watkins in Gerong } \\
\text { (1999) }\end{array}$ & $\begin{array}{l}\text { Razlike v konceptu sebstva } \\
\text { iste nacionalne skupine } \\
\text { (Filipinci), če odgovarjajo } \\
\text { v maternem jeziku in v } \\
\text { angleščini. }\end{array}$ & $\begin{array}{l}\text { A. idiocentrično; B. majhna skupina; C. } \\
\text { velika skupina; D. alocentrično }\end{array}$ & $\begin{array}{l}76 \% \text { skladnost med } \\
\text { ocenjevalci. }\end{array}$ \\
\hline
\end{tabular}

Opomba: Iz nabora 40 raziskav je v tabeli prikazanih 15 raziskav, ki najbolje predstavljajo različne načine kodiranja. 
Watkins in Gerong (1999) sta svoje kategorije definirala na naslednji način: idiocentrično (A) - izjave o lastnih prepričanjih, stališčih, osebnostnih potezah, ki se ne nanašajo na druge ljudi (sem iskren, vesel, inteligenten); alocentrično (B) - izjave o odvisnosti od drugih, prijateljstvu, občutljivosti in na kakšen način nas drugi zaznavajo (rad pomagam drugim; prepoznam, če je kdo jezen name); velike skupine (C) - izjave o članstvu v veliki skupini (sem študent, ženska, športnik); male skupine (D) - izjave o članstvu v malih skupinah, najpogosteje o družini (sin, mati, dedek).

Ma in Schoeneman (1997) sta aplicirala TST z manjšimi spremembami, udeležencem sta namreč dala na razpolago le 15 odgovornih črt in čas reševanja skrajšala na 5 do 6 minut, osnovno navodilo pa je ostalo nespremenjeno. Kodiranje je bilo naslednje: A - pripisane lastnosti (spol, starost, ime, rasa, religioznost); B - vloge in članstvo (sorodstvo, poklic, fakulteta, politična opredeljenost, socialni status, državljanstvo in članstvo v skupinah); C abstraktno identificiranje (eksistencialni opisi, članstvo $\mathrm{V}$ abstraktni kategoriji, ideološka ali religiozna prepričanja); D - interesi in aktivnosti (sodbe, preference, umetniške aktivnosti in aktivnosti na splošno); E - materialne reference (lastnina, dobrine, fizični videz); F - sistemski čut sebstva (občutek celovitosti, moralnost, kompetentnost, samodeterminacija); G - osebne značilnosti (na kakšen način razmišljam in čutim; osebni slog vedenja); H zunanji pomen (sodbe, pripisane od drugih; trenutne reference in odgovori, ki jih ni bilo mogoče umestiti $\mathrm{v}$ dane kategorije). To shemo za kodiranje sta prevzela po Gordonu (1968; v Ma in Schoeneman, 1997).

Kategorije kodiranja pri ostalih avtorjih so podobne predhodno opisanim, bodisi so definicije kategorij enake, a se imenujejo drugače, bodisi so kombinacija dveh ali več manjših podkategorij v eno večjo.

\section{Celovita evaluacija TST}

TST je nestrukturirani test in posledično zelo prilagodljiv različnim raziskovalnim potrebam. Kot smo prikazali predhodno, obstajajo različni načini kodiranja vsebine samoopisov, ki jih lahko razdelimo v dve večji kategoriji: 1)jaz(opisi, ki obsegajo zunanji videzin psihične lastnosti; torej vsi opisi, ki se nanašajo na posameznika) in 2) socialni jaz (opisi posameznika v različnih socialnih vlogah in vse aktivnosti, ki vključujejo druge ljudi ali sociokulturne institucije). V nadaljevanju podajamo evalvacijo TST po različnih strukturnih vidikih.

\section{Navodilo in teorija TST}

Izvorno navodilo TST se glasi:

» Spodaj je oštevilčenih 20 praznih črt. Prosimo, odgovorite na vprašanje »Kdo sem jaz?« na prazne črte. Napišite 20 različnih odgovorov. Odgovarjajte, kot da odgovarjate samemu sebi, ne nekomu drugemu. Odgovore zapišite, kot vam pridejo na misel. Ne skrbite za njihovo logičnost ali pomen. Čas je omejen, zato z odgovori pohitite.« (Kuhn in McPartland, 1954, str. 69).

Tucker (1966) izpostavlja, da navodilo napeljuje na implicitni sklep, da posameznik poseduje znanje o sebi in ga zna ubesediti. Pri tem lahko poudarimo, da so TST uporabili $\mathrm{v}$ različnih raziskovalnih kontekstih oziroma v različnih starostnih skupinah. Montemayor in Eisen (1977) sta s TST preverjala razvoj pojmovanja sebstva pri otrocih, starih devet let in več; že predhodno omenjena študija McPartlanda in sodelavcev (1961) je bila izvedena med pacienti na psihiatričnem oddelku. Na podlagi teh študij lahko sklepamo, da večina posameznikov poseduje znanje o sebi, ki se spreminja in razvija skladno $\mathrm{z}$ izkušnjami (McPartland idr., 1961; Montemayor in Eisen, 1977). Pomembnejši od samega znanja o sebi je torej dostop do le-tega ali drugače povedano, katere kognitivne sheme so v nekem trenutku aktivirane. Raziskave so tako pokazale vpliv pripravljalnega dražljaja, kjer so eno skupino izpostavili zaimkoma »jaz« in »moje«, drugo pa »mi« in »naše« ter skladno s tem dobili rezultate, ki so v večini izpostavljali ali osebne ali pa skupinske opise (Brewer in Gardner, 1996; Gardner, Gabriel in Lee, 1999). Posledično torej odgovor na TST vprašanje »Jaz sem ...« verjetno ni najbolj adekvaten, še posebej če je namen raziskave primerjanje individualistične in kolektivistične kulture.

$\mathrm{Na}$ podlagi Kuhnove teorije in simboličnega interakcionizma Tucker (1966) nadalje poudarja, da so stališča, ki jih posameznik napiše, nesmiselna brez razumevanja konteksta. Fokus testa so stališča ali akcijski načrt posameznika, ki je lahko razumljen le $\mathrm{v}$ kontekstu tistega, za katerega je ta načrt izdelan. Pri TST pa je analitik tisti, ki določa pomen izjav posameznika, še posebej $\mathrm{v}$ prvi različici kategoriziranja odgovorov (Tucker, 1966). Prvotna dihotomna razdelitev kodiranja (na konsenzualne in podkonsenzualne izjave) pa je sporna tudi za R. C. Wylie (1974), ki meni, da so to presplošne in slabo definirane kategorije. Povedano drugače, analitik ima preveč svobode, kar je precej splošna kritika nestrukturiranih testov; če temu dodamo še vpliv pripravljalnega dražljaja, je posledica manjša zanesljivost testa (Foels in Tomcho, 2009).

Z leti je posledično nastalo več kategorij kodiranja, ki so bile tudi bolje definirane. Iz naše analize je razvidno, da je skladnost med ocenjevalci zadovoljiva (tabela 1), čeprav je bila le-ta visoka (nad 97 \%) že v prvi verziji testa (Kuhn in McPartland, 1954). Razlog za visoko skladnost med različnimi ocenjevalci je, da vsi kodirajo odgovore po enakih kriterijih oziroma po enaki klasifikacijski shemi (McPhail in Tucker, 1972). Razen visoke skladnosti med ocenjevalci je bila visoka tudi korelacija test-retest in je v prvotni verziji TST znašala 0,85 , vendar avtorja nista navedla časovnega razmika med obema testiranjema (Kuhn in McPartland, 1954). Glede na dihotomno kodiranje visoka korelacija ne preseneča. Morda je ob tem pomembno poudariti naslednje: »upoštevajoč pojem 
koncepta sebstva kot organizacije preteklih in sedanjih socialnih izkušenj, lahko sklepamo, da vsak izrazit premik v socialni izkušnji terja rekonceptualizacijo sebstva« (McPartland idr., 1961, str. 117).

Pripravljalnemu dražljaju in izkušnjam lahko dodamo še posrednejše kontekstualne vplive, kot to ponazarjajo v svoji raziskavi Steck, Heckert in Heckert (2003). V raziskavi so potrdili hipotezo, da bodo črnski študentje v primerjavi s svojimi belskimi kolegi na fakulteti, kjer so belci številčnejši, bolj poudarjali svojo rasno identiteto. Drugače povedano, okolje, v katerem oseba rešuje vprašalnik, lahko deluje kot (znova) pripravljalni dražljaj za določene samoopise.

\section{Konstruktna veljavnost TST}

Spitzer, Stratton, Fitzgerald in Mach (1966) so primerjali TST, ki je odprt vprašalnik, in vprašalnike $s$ predhodno določenimi odgovori (pridevniki). Ker je TST na nominalnem merskem nivoju, so prosili udeležence, da vsak samoopis ovrednotijo na 4-stopenjski lestvici. Upoštevali so samo tiste opise, ki se nanašajo na samoevalvacijo. Dodatno so vključili še vprašalnike in tehnike, in sicer Indeks prilagoditve in vrednot (Index of Adjustment and Values (IAV); Bills, 1951, v Spitzer idr., 1966), Ček listo pridevnikov (Adjective Checklist (ACL); Gough in Heilbrun, 1958, v Spitzer idr., 1966) in Tehniko semaintičnega diferenciala (Semantic Differential Technique; (FSD); Fiedler, Hutchins in Dodge, 1959, v Spitzer idr., 1966). Interna konsistentnost testa dveh dimenzij ACL je 0,78, za dimenziji FSD znaša 0,62, povprečje treh dimenzij IAV je 0,66 , povprečje štirih dimenzij TST pa 0,35 (Spitzer idr., 1966). Korelacija med konstrukti s predhodno določenimi odgovori je segala od 0,39 do 0,67 , korelacija med odprtim vprašalnikom (TST) in ostalimi konstrukti pa je bila $\mathrm{v}$ glavnem negativna. Ko so posamezniki izpolnili vprašalnike, so morali odgovoriti na vprašanje, kateri od vprašalnikov omogoča najbolj natančen opis sebe in kateri tega ne omogoča (Spitzer idr., 1966, str. 271). ACL je bil označen kot vprašalnik, s katerim so se lahko izrazili, medtem ko so za TST, poročali, da se niso mogli.

Spitzer (1969) poudarja problem testiranja enakovrednosti testov. Namreč, korelirajo tisti testi, ki naj bi merili enak konstrukt ( $v$ tem primeru sebstvo), težava pa je, da večina testov $\mathrm{v}$ omenjeni raziskavi ne meri sebstva, temveč elemente, iz katerih sebstvo sestoji (npr. samoevalvacija, samospoštovanje, sprejemanje samega sebe). Spitzer še dodaja, da »domnevna podobnost (testa) ne zagotavlja podobnosti konstrukta, ki ga ocenjujemo« (Spitzer, 1969, str. 205). V nadaljnjem delu je avtor izvedel raziskavo, v kateri je $\mathrm{v}$ testno baterijo vključil sledeče teste: TST, modificirani TST (MOD) (ki se razlikuje od predhodnega samo v vprašanju Kakšna oseba sem?), Test tematskeapercepcije(TAT), Rorschachov test, Projekcijsko tehniko nedokončanih stavkov (Projective Sentence Completions (PSC); Sacks, 1966, v Spitzer, 1969) in Test repertoarja vlog (Role Repertory Test (RRT); Kelly, 1966, v Spitzer, 1969). Odgovore na TST so klasificirali tako, da so sešteli število negativnih samoopisov in določili rang prve negativne izjave; pri modificirani obliki TST (MOD) pa so ob oceni negativnih opisov izračunali tudi oceno samozadovoljstva, ki je seštevek pozitivnih samoopisov. Največja pozitivna korelacija je bila med negativnimi izjavami TST in MOD, in sicer 0,36 , največja negativna korelacija pa med negativnimi izjavami TST in PSC. Na splošno so korelacije med testi negativne ali pa testni rezultati sploh niso povezani. Na podlagi rezultatov je Spitzer (1969) povzel, da odprti vprašalniki, ki merijo pojmovanje sebstva, niso ekvivalentni.

Spitzer in Parker sta $\mathrm{v}$ raziskavi leta 1976 ponovno uporabila baterijo vprašalnikov, ki je vsebovala TST, FSD, IAV in ACL. Tudi tokrat ju je zanimal odgovor na vprašanje, ki je bilo zastavljeno v raziskavi deset let prej (Spitzer idr., 1966). TST je bil označen kot vprašalnik, s katerim se lahko posameznik najbolje izrazi, ACL pa kot test, s katerim se najslabše. Razlog za omenjeno spremembo lahko po navajanju avtorjev iščemo $\mathrm{v}$ vse večji pomembnosti sebstva v kulturi, pa tudi v znanju o sebstvu kot holistični strukturi.

Na področju medkulturnih študij se je TST uveljavil kot instrument za ugotavljanje podobnosti in različnosti v pojmovanju sebstva (Cross, Hardin in Gercek-Swing, 2011), še posebej v kontekstu razlikovanja med neodvisnim in soodvisnim pojmovanjem sebstva po H. R. Markus in Kitayami (1991). S. L. Grace in Cramer (2003) sta v svoji študiji preverjala instrumente, ki merijo pojmovanje sebstva, in sicer Lestvico neodvisnega in soodvisnega sebstva (Self-Construal Scale (SCS); Singelis, 1994, v Grace in Cramer, 2003) in TST. TST odgovore sta kodirala $\mathrm{v}$ štiri skupine, in sicer $\mathrm{v}$ alocentrične in idiocentrične izjave ter male in velike skupine (glej kodiranje odgovorov po Watkinsu in Gerongu (1999) v tabeli 1). Rezultati so pokazali statistično značilno pozitivno korelacijo med soodvisnim pojmovanjem sebstva in alocentričnimi izjavami, a hkrati ni bilo statistično značilne korelacije med neodvisnim pojmovanjem sebstva in idiocentričnimi izjavami, kot tudi ne razlik med spoloma v odgovorih, kar bi bilo glede na teorijo pričakovano. Avtorja iz slednjega sklepata, da SCS in TST ne merita istega konstrukta.

M. J. Bresnahan in sodelavci (2005) so izvedli podobno raziskavo, v kateri so uporabili SCS, Lestvico relacijskega soodvisnega pojmovanja sebstva (RelationalInterdependent Self-Construal Scale (RISC); Cross, Bacon in Morris, 2000; v Bresnahan idr., 2005) in TST. Odgovore na TST so kodirali v tri kategorije. Prva se je nanašala na avtonomne in edinstvene značilnosti posameznika, kaj ustreza neodvisnem pojmovanju sebstva; druga kategorija je zajemala povezanost s skupino, kaj ustreza kolektivnem soodvisnem pojmovanju sebstva; tretja kategorija se je navezovala na odnose, kaj ustreza relacijskemu soodvisnem pojmovanju sebstva. Korelacije med vprašalnikoma SCS in RISC ter TST so bile bodisi nizke ali negativne in avorji so prišli do podobnega zaključka kot S. L. Grace in Cramer (2003). 
Zanimivo je tudi vprašanje, katero mesto zaseda TST v večji bateriji testov. V obeh predhodno omenjenih raziskavah Spitzerja (Spitzer idr., 1966; Spitzer in Parker, 1976) so udeleženci najprej reševali TST in so bili primorani poiskati odgovor v spominu. Če bi TST dali na konec, bi lahko posameznik zgolj potrdil odgovore na prejšnje teste (Spitzer in Parker, 1976). Seveda pa se ob tem znova postavi vprašanje učinka pripravljalnega dražljaja in se izgubi samo bistvo odprtega vprašalnika.

\section{Uporabna vrednost TST}

Če povzamemo, je TST zelo fleksibilen instrument, ki ga lahko raziskovalec enostavno in učinkovito prilagaja raznolikim raziskovalnim potrebam in okoliščinam. Na to kažejo med drugim tudi različne možnosti kodiranja, od elaboriranih z več kategorijami pa vse do verzij, kjer je kodiranje osredotočeno na eno kategorijo in je poudarek na pogostosti točkovanja (Steck idr., 2003).

Kot je bilo predhodno navedeno, je korelacija znotraj samega testa in med podobnimi konstrukti, najsi so to strukturirani ali nestrukturirani testi, nizka ali je sploh ni (Spitzer idr., 1966; Spitzer, 1969). TST bi tako popolnoma zadovoljil le dva kriterija dobrega testa, in sicer objektivnost in ekonomičnost (Bucik, 1997).

Instrument se je sicer glede na prvo različico (Kuhn in McPartland, 1954) razvijal in obstajajo določene strategije, s katerimi dobimo podrobnejše informacije o posameznikovih izjavah. Nekateri raziskovalci so testu dodali navodilo, da naj posameznik sam oštevilči izjave glede na stopnjo pomembnosti, ki jo zanj predstavlja (Cousins, 1989; McPhail in Tucker 1972;), spet drugi so nominalne spremenljivke spremenili v ordinalne, tako da so morali posamezniki na 4-stopenjski lestvici označiti, kako močno veljajo te izjave za njih (Spitzer, 1969; Spitzer idr.,1966). To so manjše modifikacije, s katerimi se v osnovi struktura testa ne spreminja, izboljša pa se kakovost interpretacije podatkov.

Vsekakor lahko izpostavimo, da je test uporaben v pedagoško-didaktične namene. Stimson in Stimson (1978) sta ga uporabila, da bi se študenti naučili klasifikacije odgovorov in drugih osnovnih statističnih metod. Tudi $\mathrm{V}$ medkulturnih študijah se je test, sicer $\mathrm{z}$ majhnimi spremembami v navodilih, izkazal za uporabnega in se ga še dandanes uporablja za merjenje pojmovanja sebstva (Isbell, McCabe, Burns in Lair, 2013; Lam idr., 2014; Santamaria idr., 2010). Pri tem je na mestu vodilo A. M. del Prado s sodelavci (2007), ki predlagajo, da naj se analitik pri vrednotenju izjav bolj osredotoča na napisano, kot pa da le-to uvrsti v dano kategorijo.

Dodatna dobra stran vprašalnikov tipa TST je, da posameznik sam napiše informacije o sebi in s tega vidika ga lahko uporabimo v triangulaciji. Pri tem pa je glede na predhodne raziskave dobro biti pozoren na to, kakšno informacijo želimo oziroma ali bomo TST ponudili za reševanje kot prvi test ali kot zadnjega (Spitzer in Parker, 1976).
Naj zaključimo z besedami, da četudi ima TST določene slabosti, to še ne pomeni, da so informacije, ki jih tako dobimo o posamezniku, neuporabne. Navsezadnje nam lahko prav v kombinaciji verifikacije z drugimi tehnikami in načini pridobivanja informacij poda celovitejši odgovor na vprašanje »Kdo smo?«.

\section{Literatura}

Bond, M. H. in Cheung, T. S. (1983). College students' spontaneous self-concept: The effect of culture among respondents in Hong Kong, Japan, and the United States. Journal of Cross-Cultural Psychology, 14, 153-171. doi: 10.1177/0022002183014002002.

Bresnahan, M. J., Levine, T. R., Shearman, S. M., Lee, S. Y., Park, C. in Kiyomiya T. (2005). A multimethod multitrait validity assessment of self-construal in Japan, Korea, and the United States. Human Communication Research 31(1), 33-59.

Brewer, M. B. in Gardner, W. (1996). Who is this "We"? Levels of collective identity and self representations. Journal of Personality and Social Psychology, 71(1), 83-93.

Bucik, V.(1997). Osnovepsihološkegatestiranja.Ljubljana: Filozofska fakulteta, Oddelek za psihologijo.

Church, A. T. (2009). Prospects for an integrated trait and cultural psychology. European Journal of Personality, 23, 153-182. doi: 10.1002/per.700.

Cousins, S. D. (1989). Culture and self-perception in Japan and the United States. Journal of Personality and Social Psychology, 56, 124-131.

Cross, S. E., Hardin, E. E. in Gercek-Swing, B. (2011). The what, how, why, and where of self-construal. Personality and Social Psychology Review, 15(2), 142-179. doi: 10.1177/1088868310373752.

del Prado, A. M., Church, A. T., Katigbak, M. S., Miramontes, L. G., Whitty, M. T., Curtis, G. J. ... Reyes, J. A. S. (2007). Culture, method, and the content of self-concepts: Testing trait, individualself-primacy, and cultural psychology perspectives. Journal of Research in Personality, 41, 1119-1160. doi: 10.1016/j.jrp.2007.02.002.

Dhawan, N., Roseman, I. J., Naidu, R. K., Thapa, K. in Rettek, S. I. (1995). Self-concepts across two cultures: India and the United States. Journal of Cross-Cultural Psychology, 26, 606-621. doi: 10.1177/002202219502600606.

Driver, E. D. (1969). Self-conceptions in India and the United States: A cross-cultural validation of the Twenty Statement Test. The Sociological Quarterly, 10(3), 341-354.

Foels, R. in Tomcho, T. J. (2009). Gender differences in interdependent self-construals: It's Not the type of group, it's the way you see it. Self and Identity, 8, 396-417. doi: 10.1080/15298860802391470. 
Gardner, W. L., Gabriel, S. in Lee, A. Y. (1999). "I" value freedom, but "We" value relationships: Self-construal priming mirrors cultural differences in judgment. Psychological Science, 10(4), 321-326.

Grace, S. L. in Cramer, K. L. (2003). The elusive nature of self-measurement: The self-construal scale versus the twenty statements test. The Journal of social Psychology, 143(5), 649-668.

Isbell, L. M., McCabe, J., Burns, K. C. in Lair, E. C. (2013). Who am I? The influence of affect on the working self-concept. Cognition and Emotion, 27(6), 1073-1090. doi: 10.1080/02699931.2013.765388.

Kanagawa, C., Cross, S. E. in Markus, H. R. (2001). "Who Am I?" The cultural psychology of the conceptual self. Personality and Social Psychology Bulletin, 27, 90-103, doi: 10.1177/0146167201271008.

Kuhn, M. H. (1960). Self-attitudes by age, sex, and professional training. The Sociological Quarterly, 1(1), 39-56.

Kuhn, M. H. in McPartland, T. S. (1954). An empirical investigation of self-attitudes. American Sociological Review, 19(1), 68-76.

Lam, M., Chan, G., Marcet, M. M., Wong, W., Wong, J, in Wong, D. (2014). Spontaneous self-concept among Chinese undergraduates in Hong Kong. Social Behavior and Personality, 42(8), 1353-1364. doi:10.2224/sbp.2014.42.8.1353.

Ma, V. in Schoeneman, T. J. (1997). Individualism versus collectivism: A comparison of Kenyan and American self-concepts. Basic and Applied Social Psychology, 19(2), 261-273.

Madson, L. in Trafimov, D. (2001). Gender comparisons in the private, collective, and allocentric selves. The Journal of Social Psychology, 141(4), 551-559.

Markus, H. R. in Kitayama, S. (1991). Culture and the self: Implications for cognition, emotion, and motivation. Psychological Review, 98(2), 224-253. doi: 10.1037/0033-295X.98.2.224.

McPahil, C. in Tucker, C. W. (1972). The classification and ordering of responses to the question "Who Am I?". The Sociological Quarterly, 13(3), 329-347.

McPartland, T. S., Cumming, J. H. in Garretson, W. S. (1961). Self-conception and ward behaviour in two psychiatric hospital. Sociometry, 24(2), 111-124.

Mead, G. H. (1934). Mind, self, and society. London: The University of Chicago Press.

Montemayor, R. in Eisen, M. (1977). The development of self-conceptions from childhood to adolescence. Developmental Psychology, 13(4), 314-319.

Rhee, E., Uleman, J. S., Lee, H. K. in Roman, R. J. (1995). Spontaneous self-descriptions and ethnic identities in individualistic and collectivistic cultures. Journal of Personality and Social Psychology, 69(1), 142-152.

Santamaria, A., de la Mata, M., Hansen, T. G. B. in Ruiz, L. (2010). Cultural self-construals of Mexican, Spanish, and Danish college students: Beyond independent and interdependent self. Journal of Cross-Cultural Psychology, 41(3), 471-477. doi: 10.1177/0022022109359694.
Spitzer, S. P. (1969). Test equivalence of unstructured selfevaluation instruments. The Sociological Quarterly, 10(2), 204-215.

Spitzer, S. P. in Parker, J. (1976). Perceived validity and assessment of the self: A decade later. The Sociological Quarterly, 17(2), 236-246.

Spitzer, S. P., Stratton, J. R., Fitzgerald, J. D. in Mach, B. K. (1966). The self concept: Test equivalence and perceived validity. The Sociological Quarterly, 7(3), 265-280.

Steck, L. W., Heckert, D. M. in Heckert, D. A. (2003). The salience of racial identity among African-American and white students. Race and Society, 6, 57-73. doi: 10.1016/j.racsoc.2004.09.005.

Stimson, J. in Stimson, A. (1978). Using the "Who am I?" Test to teach the logic of four-fold tables. Teaching Sociology, 5(3), 281-286.

Triandis, H. C., McCusker, C. in Hui, C. H. (1990). Multimethod probes of individualism and collectivism. Journal of Personality and Social Psychology, 59(5), 1006-1020.

Tucker, C. W. (1966). Some methodological problems of Kuhn's self theory. The Sociological Quarterly, 7(3), 345-358.

Vernon, G. M. (1962). Measuring religion: Two methods compared. Review of Religious Research, 3(4), 159-165.

Watkins, D., Cheng, C., Mpofu, E., Olowu, S., SinghSengupta, S. in Regmi, M. (2003). Gender differences in self-construal: How generalizable are Western findings. The Journal of Social Psychology, 143(4), 501-519.

Watkins, D. in Gerong, A. (1997). Culture and spontaneous self-concept among Filipino college students. The Journal of Social Psychology, 137(4), 480-488.

Watkins, D. in Gerong, A. (1999). Language of response and the spontaneous self-concept: A test of the cultural accommodation hypothesis. Journal of Cross-Cultural Psychology, 30(1), 115-121. doi: 10.1177/0022022199030001007.

Wylie, R. C. (1974). The self concept: A review of methodological considerations and measuring instruments. Nebraska, ZDA: University of Nebraska press. 